Research Article

\title{
Active Fraction Combination from Liuwei Dihuang Decoction (LW-AFC) Alleviated the LPS-Induced Long-Term Potentiation Impairment and Glial Cells Activation in Hippocampus of Mice by Modulating Immune Responses
}

\author{
Ju Zeng, ${ }^{1,2}$ Bin Cheng, ${ }^{1,2}$ Yan Huang $\mathbb{D}^{1,2}$ Xiaorui Zhang, ${ }^{1,2}$ Chen Wang, ${ }^{1,2}$ Na Sun, \\ Gang Liu, ${ }^{1,2}$ Xiaorui Cheng $\mathbb{D}^{1,2}$ Yongxiang Zhang $\mathbb{D}^{1,2}$ and Wenxia Zhou $\mathbb{D}^{1,2}$ \\ ${ }^{1}$ Beijing Institute of Pharmacology and Toxicology, Beijing 100850, China \\ ${ }^{2}$ State Key Laboratory of Toxicology and Medical Countermeasures, Beijing 100850, China
}

Correspondence should be addressed to Xiaorui Cheng; chengxiaorui@hotmail.com, Yongxiang Zhang; zhangyx@bmi.ac.cn, and Wenxia Zhou; zhouwx@bmi.ac.cn

Received 11 March 2019; Revised 3 June 2019; Accepted 2 July 2019; Published 16 September 2019

Academic Editor: Junqing Yang

Copyright ( $2019 \mathrm{Ju}$ Zeng et al. This is an open access article distributed under the Creative Commons Attribution License, which permits unrestricted use, distribution, and reproduction in any medium, provided the original work is properly cited.

\begin{abstract}
Neuroinflammation is known as a typical feature associated with many neurodegenerative diseases including Alzheimer's disease (AD) and impairs the synaptic plasticity of the hippocampus. LW-AFC is an active fraction combination being extracted from Liuwei Dihuang decoction, a classic traditional Chinese medicine prescription. This study aimed to investigate the effects of LWAFC on synaptic plasticity in mice with lipopolysaccharide (LPS) treatment. The results showed that the administration of LPS caused fever and long-term potentiation (LTP) impairment in mice. The pretreatment with LW-AFC had an antipyretic effect on fever and improved the impaired LTP induced by LPS, alleviated the microglia and astrocytes activation in the hippocampus, regulated the abnormal T-lymphocyte subpopulation in the spleen and blood caused by LPS, and reduced the aberrant secretion of cytokines in the brain and plasma. The compounds paeoniflorin, morroniside, and loganic acid in LW-AFC regulated the TNF- $\alpha$ secretion in non-LPS- and LPS-stimulated BV-2 cells. These data suggest that LW-AFC improves the LPS-induced impairment of LTP and alleviates the activation of glial cells in the hippocampus, which might be associated with modulating immune responses.
\end{abstract}

\section{Introduction}

Neuroinflammation is known as a typical feature associated with many neurodegenerative diseases, including Alzheimer's disease $(\mathrm{AD})$ [1-7]. Neuroinflammation is noteworthy because increased inflammation is harmful to the local brain environment and produces synaptoxic and neurotoxic effects $[8,9]$ associated with cognitive impairment $[10,11]$. Growing evidence indicates that systemic administration of lipopolysaccharides (LPSs) stimulates the inflammatory response in the brain [12-14]. This is a commonly used model of neuroinflammation, which leads to an increased secretion of proinflammatory cytokines like tumor necrosis factor alpha (TNF- $\alpha$ ), interleukin-1 (IL-1), and interleukin-6 (IL-6) in the brain immune system [1517]. The elevated cytokine levels mediate sickness behavior and alter cognitive processes accompanied by the occurrence of neuroinflammation $[14,18]$. The inflammatory response impairs the synaptic plasticity of the hippocampus $[13,19]$.

Reducing inflammation is one of the most effective treatment strategies to improve cognitive impairment. Selective cyclooxygenase-2 (COX-2) inhibitors, like celecoxib, ibuprofen, and indomethacin, whose anti-inflammatory and analgesic effects partly result from the inhibition of prostaglandin synthesis, are clinically used to treat pain and arthritis. In subsequent years, a host of experimental studies have reported the $\mathrm{A} \beta$-lowering effects and cognitive improvement of these drugs in cell-based and animal models of 
Alzheimer's disease or clinical trials [20, 21]. Proinflammatory cytokine tumor necrosis factor alpha (TNF- $\alpha$ ) inhibitor etanercept has been used in clinical research and is expected to inhibit the activation of microglia by its antiinflammatory action to improve the cognitive effect of $\mathrm{AD}$ patients $[22,23]$.

LW-AFC is a new formula derived from the Liuwei Dihuang decoction, which is a classic traditional Chinese medicine prescription. LW-AFC is composed of glycosides, oligosaccharides, and polysaccharides. Our previous studies have shown that LW-AFC has good immunological activity [24] and can improve cognitive performance in sporadic and family AD model mice, such as the senescence-accelerated mouse prone 8 strain (SAMP8) and APP/PS1 transgenic mice $[25,26]$. The impairments in long-term potentiation (LTP) were significantly improved by LW-AFC administration in SAMP8 mice and in the corticosterone-induced LTP inhibition mice model [27]. LW-AFC can significantly reduce $\mathrm{A} \beta$ plaque aggregation in the brain of $\mathrm{APP} / \mathrm{PS} 1$ transgenic mice [25]. All these studies imply that LW-AFC is a promising effective drug for $\mathrm{AD}$ treatment; however, whether LW-AFC has any therapeutic effect on LPS-treated mice and the underlying mechanisms remain unclear, thus warranting further investigation. The present study aimed to investigate the effects of LW-AFC on the synaptic plasticity and the immunomodulatory effects of LW-AFC on the inflammatory responses in LPS-treated mice in order to elucidate whether LW-AFC could improve synaptic plasticity impairment by regulating immune dysfunction.

\section{Materials and Methods}

2.1. Animals. A total of 70 male $2-4$ months BALB/c mice were purchased from Weitong Lihua Experimental Technology Co. Ltd. (Beijing, China). Mice weighing 19-21 g were housed in cages maintained at $23 \pm 1^{\circ} \mathrm{C}$ with food and water and a $12: 12 \mathrm{~h}$ dark/light cycle. Mice were acclimatized to the laboratory environment for at least one week prior to the experiment. The animal received human care according to the National Institutes of Health (USA) guidelines, approved by the Institute of Animal Care and Use Committee (IACUC) of the National Beijing Center for Drug Safety Evaluation and Research (NBCDSER) (No. 2018-030).

2.2. Drug and Reagents. The origin herbal drug of LW was purchased from Beijing Tongrentang Co., Ltd. (Beijing, China). LW-AFC is comprised of glycosides, oligosaccharides, and polysaccharides extracted from LW. Details of the extraction of LW-AFC can be seen in [26]. We chose indomethacin ( $\geq 98 \%$, Ouhe Technology Co., Ltd., Beijing, China) as a compound that has a positive effect on the inflammatory response. Lipopolysaccharides (L2880, Sigma, St. Louis, MO, USA), PEG400 (30150892, Sinopharm Group Chemical Reagent Co., Ltd. Shanghai, China), mouse cytokines/chemokines kit (9MPXMCYTO-70K-06, Merck Millipore, Boston, MA, USA), BD FACS ${ }^{\mathrm{TM}}$ Lysing Solution (349202, BD), 4\% paraformaldehyde, saline, 75\% alcohol, $4 \%$ EDTA-Na2, and PBS.
2.3. Drug Administration. LW-AFC was intragastrically administered in $0.8,1.6$, or $3.2 \mathrm{~g} / \mathrm{kg}$ doses for 14 days. $2.5 \mathrm{mg} / \mathrm{kg}$ indomethacin was used as the positive drug with a single intraperitoneal (i.p.) injection on the last day. All drugs were administered in an equivalent volume of $0.1 \mathrm{~mL} / 10 \mathrm{~g}$ body weight of the mouse. Model group and drug groups were intraperitoneally administered LPS $0.25 \mathrm{mg} / \mathrm{kg} 30 \mathrm{~min}$ after being given the drug on the 14th day.

2.4. Temperature Test. We employed an electronic thermometer to measure the neck temperature of the mice $6 \mathrm{~h}$ after the LPS i.p. injection.

2.5. In Vivo LTP Test. Mice were anesthetized with urethane $1.5 \mathrm{~g} / \mathrm{kg}$ i.p., and then we used the stereotaxic apparatus (SR$6 \mathrm{~N}$, Narishige Inc., Tokyo, Japan) to fix the mouse. The mouse scalp was cut, the hippocampal PP-DG (anterior penetrating fiber-dentate granule cell layer) position was located, a hole was drilled at the localization, the recording electrode was inserted into the DG $(2.0 \mathrm{~mm}$ after the anterior fontanel, $1.4 \mathrm{~mm}$ beside the midline, and $1.5 \mathrm{~mm}$ under the subdural layer), the stimulating electrode was inserted into the PP (3.8 $\mathrm{mm}$ after the anterior fontanel, $3.0 \mathrm{~mm}$ beside the midline, and $1.5 \mathrm{~mm}$ under the subdural layer), and the reference electrode was clamped on the scalp. During the experiment, the environment was kept quiet. A population spike (PS, bandwidth: $100 \mu \mathrm{s}$, current intensity: $0.3 \mathrm{~mA}$ ) was conducted, and the electrodes were modulated to achieve the best PS wave shape. After 30 60 min, the stimulating intensity was decreased to half the PS wave and then was kept stable for $30 \mathrm{~min}$ and recorded as the baseline. Then, tetanic stimulation (TS) was given to induce long-term potentiation (LTP) and recode the PS wave for $60 \mathrm{~min}$.

2.6. Immunofluorescence Staining. Animals were sacrificed after the LTP test. Brains were subsequently removed from the skull after decapitation and perfused with PBS. Each brain was cut into two hemispheres. Tissues of the hippocampus and cortex in one hemisphere were separated and then frozen in liquid nitrogen for detecting the concentration of cytokines. The other hemisphere was immersion fixated in $4 \%$ paraformaldehyde, embedded in paraffin, and then cut into $5 \mu \mathrm{m}$ thick sections for immunofluorescence staining. The sections were incubated in $2 \%$ fetal bovine serum for $1 \mathrm{~h}$ and then were incubated with the primary antibodies of rabbit anti-Iba1 (1:500; Abcam, Cambridge, UK) and rabbit anti-GFAP (1:1000; Abcam, Cambridge, $\mathrm{UK})$ to label the microglia and astrocytes at $4^{\circ} \mathrm{C}$ overnight. Then, they were incubated with the appropriate secondary antibody (goat anti-rabbit, 1:1000; Zhongshan Jinqiao, Beijing, China) for $2 \mathrm{~h}$ at room temperature. Images were captured using a Pannoramic 250/MIDI camera (3D HISTECH, Budapest, Hungary) and analyzed using Image-pro plus 6.0 software. 
2.7. Flow Cytometry Analysis. The spleen single-cell suspension was prepared by $40 \mu \mathrm{M}$ nylon cell strainer, and the red blood cells were depleted in a Tris- $\mathrm{NH}_{4} \mathrm{Cl}$ lysis buffer $\left(0.017 \mathrm{M}\right.$ Tris- $\left.\mathrm{HCl}, 0.144 \mathrm{M} \mathrm{NH}_{4} \mathrm{Cl}\right)$. The cells were incubated with FITC anti-mouse CD3, Percp anti-mouse CD4, APC anti-mouse CD25, APC anti-mouse CD8 (BioLegend, San Diego, CA, USA) at room temperature for $30 \mathrm{~min}$ in the dark and then washed and resuspended in $0.5 \mathrm{~mL}$ of PBS containing $0.5 \%$ FBS and then tested by cytometry (BD Calibur $^{\mathrm{TM}}$, company, Lake Franklin, NJ, USA). The percentages of $\mathrm{CD}^{+}, \mathrm{CD}^{+} \mathrm{CD}^{+}, \mathrm{CD}^{+} \mathrm{CD} 25^{+}$, and $\mathrm{CD}^{+} \mathrm{CD}^{+}$expression was analyzed by the $\mathrm{BD}$ FACS Calibur $^{\mathrm{TM}}$ CellQuest software.

2.8. Measurement of Cytokine Concentration. The blood was dropped into a tube containing 4\% EDTA- $\mathrm{Na}_{2}$ (1:9), placed at $4^{\circ} \mathrm{C}$ for $2 \mathrm{~h}$, centrifugated at $4^{\circ} \mathrm{C}, 3000 \times g$ for $15 \mathrm{~min}$, and then the plasma was collected into clean tubes and stored at $-70^{\circ} \mathrm{C}$ for the cytokine test. The concentrations of TNF- $\alpha$, IFN $\gamma$, IL- $1 \beta$, IL-6, IL-10, IL-12, MCP-1, and G-CSF were detected by a Multiplex Map Kit (MCYTOMAG-70K, Merck Millipore, Boston, MA, USA) according to the manufacturer's instructions and analyzed with Millipore software (Merck Millipore Corp., Boston, MA, USA).

2.9. Cell Culture and Stimulation. Mouse microglia BV2 cells were cultured in high-glucose Dulbecco's Modified Eagle's Medium (DMEM) supplemented with 10\% fetal bovine serum (FBS, Gibco, Grand Island, NY, USA), 1\% penicillin, and streptomycin at $37^{\circ} \mathrm{C}$ in a humidified incubator with $95 \%$ air and $5 \% \mathrm{CO}_{2}$. Cells were seeded at $1 \times 10^{4} /$ well in a 96-well plate. When cells reached approximately $70 \%$ confluence, we removed the culture medium and pretreated them with 1,10 , and $100 \mu \mathrm{M}$ paeoniflorin, morroniside, loganic acid, stachyose, and mannotriose (J\&K Chemical, Shanghai, China) and 0.1, 1, and $10 \mu \mathrm{M}$ CA4-3 [12] for $30 \mathrm{~min}$ before adding $1 \mu \mathrm{g} / \mathrm{mL}$ LPS stimulate (L2630, Sigma, St. Louis, MO, USA) and then incubated for $24 \mathrm{~h}$. We used $25 \mu \mathrm{M}$ indomethacin and $10 \mu \mathrm{M}$ dexamethasone as a positive control.

2.10. Cell Viability Assay. After the cells were cultured for $24 \mathrm{~h}$, the cell viability was examined by a Cell Counting Kit 8 (Dojindo Laboratories, Kumamoto, Japan), according to the manufacturer's instructions. We added $10 \mu \mathrm{L}$ of CCK- 8 to each well and then incubated them at $37^{\circ} \mathrm{C}$ for $2 \mathrm{~h}$. The optical density (OD) was measured using an EnSpire ${ }^{\mathrm{TM}}$ 2300 instrument (PerkinElmer, Waltham, MA, USA) at $450 \mathrm{~nm}$.

2.11. Measurement of TNF- $\alpha$ Secretion. The secretion of TNF- $\alpha$ in the cell supernatant was determined using an AlphaLISA mouse TNF- $\alpha$ Kit (PerkinElmer, Waltham, MA, USA) according to the manufacturer's protocols using an
EnVision $^{\mathrm{TM}} 2104$ instrument (PerkinElmer, Waltham, MA, USA).

2.12. Statistical Analysis. All data were analyzed using GraphPad Prism 6.0 and are expressed as mean \pm SD. Statistical significance was determined by unpaired Student's $t$-test and one-way ANOVA and Dunnett's test. $p$ values $<0.05$ were considered significant.

\section{Results}

3.1. Antipyretic Effect of Pretreatment of $L W-A F C$ on Fever Caused by Intraperitoneal Injection of LPS. Fever is a feature of inflammation-induced symptoms. The intraperitoneal injection of LPS can trigger systemic inflammation that results in fever. In this study, to confirm that LPS induced a sickness response and investigate the effect of LW-AFC on this sickness, we measured the change in body temperature. The results showed that the body temperature in mice rose significantly after $6 \mathrm{~h}$ of a single LPS injection (Figure 1). Pretreatment with $30 \mathrm{~min}$ of indomethacin and two weeks of LW-AFC prevented the increase in temperature caused by the intraperitoneal (i.p.) injection of LPS. LW-AFC had a significant dose-dependent effect on reducing fever (Figure 1).

3.2. Pretreatment of $L W$-AFC Improved Long-Term Potentiation Impairment Induced by Intraperitoneal Injection of LPS. In order to understand the effect of LW-AFC on the cognitive change of LPS-induced mice, we firstly conducted the object recognition behavior test to investigate the temporal order memory in LPS-injected mice, but there were no significant differences in LW-AFC treatment (Supplementary Figure S1). LTP is associated with synaptic plasticity and is known as the physiological mechanism of learning and memory in the CNS [28, 29]. In this study, we found that the i.p. injection of LPS in mice (mod) caused a significant decrease in the EPSP wave when compared to the control group (con) (Figure 2, Figure S2). This suggests that system injection of LPS could induce neuroinflammation, which can impair learning and memory. Compared with the model group (mod), pretreatment with LW-AFC had a significant increasing effect on LTP at a dose of $1.6 \mathrm{~g} / \mathrm{kg}$. The data suggest that pretreatment with LW-AFC might improve the ability of learning and memory in mice treated with an intraperitoneal injection of LPS.

3.3. Pretreatment of $L W-A F C$ Alleviated Activation of Glial Cells in the Brain of Mice with Intraperitoneal Injection of LPS. Activation of the microglia and astrocytes in the brain is a typical feature of inflammation in the CNS and one of the causes of impairment of learning and memory. We found that the administration of a single LPS intraperitoneal injection significantly induced the activation of microglia (Figure 3(a)) and astrocytes (Figure 3(c)) in the brains of 


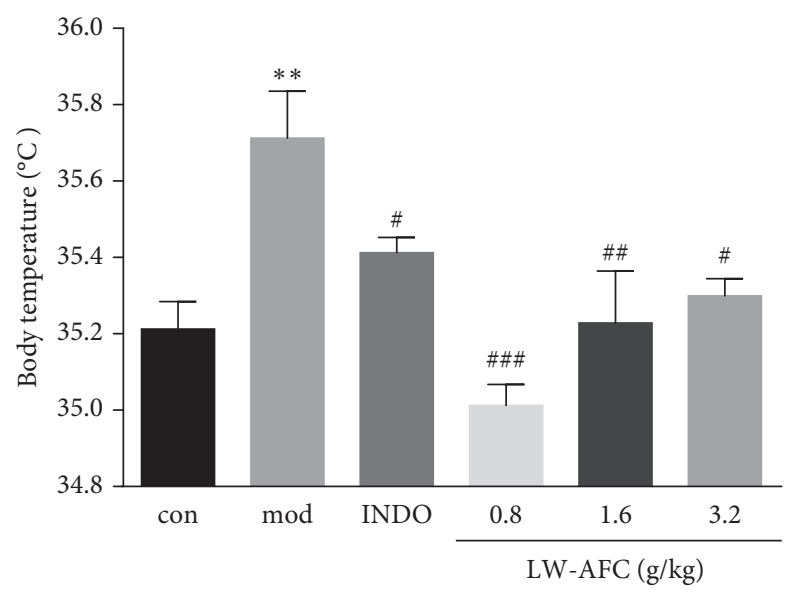

FIGURE 1: Effect of LW-AFC on body temperature in LPS-treated mice. ${ }^{* *} p<0.01 v s$. con and Student's $t$-test; ${ }^{\# \#} p<0.001$, ${ }^{\# \#} p<0.01$, and ${ }^{\#} p<0.05 v$ s. mod, one-way ANOVA, and Dunnett's test, mean $\pm \mathrm{SD}, n=8$. con, control; mod, model; INDO, indomethacin.

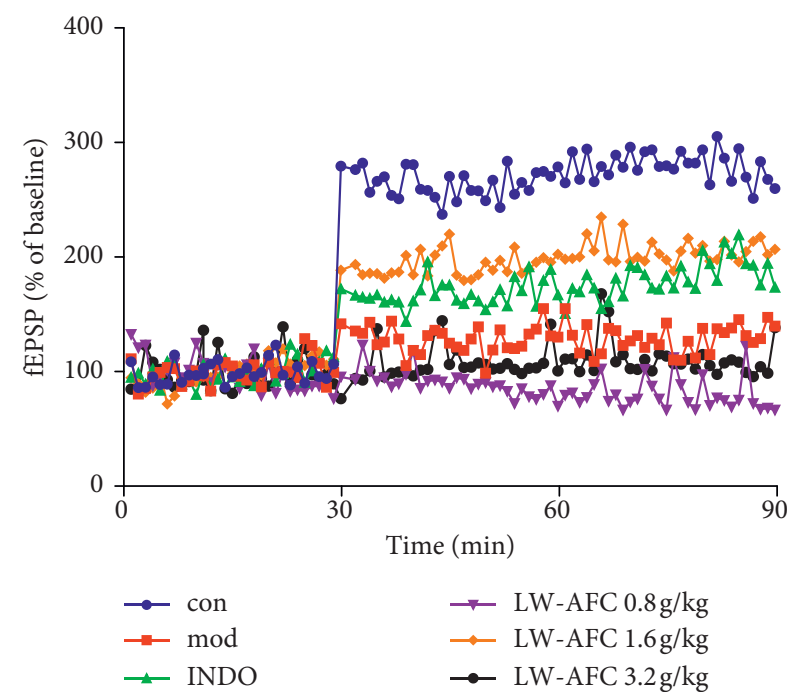

(a)

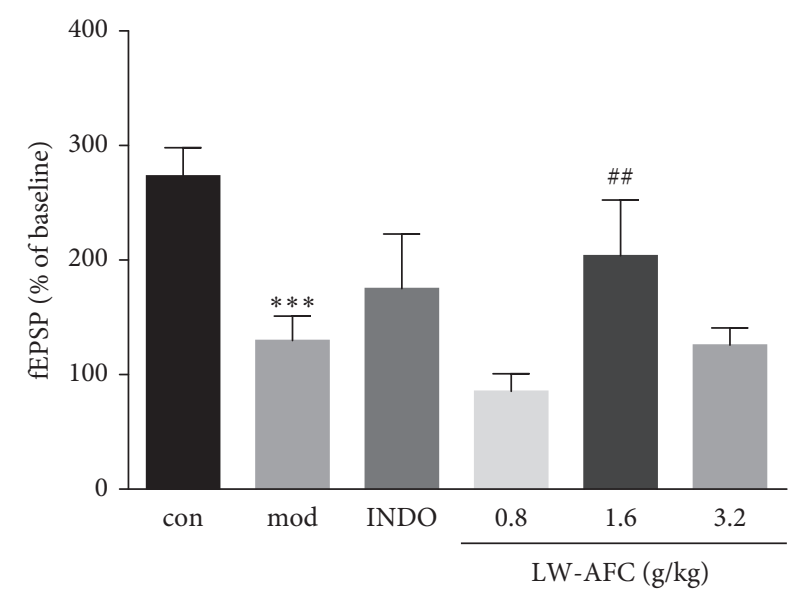

(b)

FIGURE 2: Effect of LW-AFC on LTP impairment in the hippocampus of LPS-treated mice. TS was given after 30 min baseline recording. (a) The time course of the indicated dose of LW-AFC on the population spike. (b) The average population spike in 60 min of each group. *** $p<0.001 v s$. con and Student's $t$-test; ${ }^{\# \#} p<0.01 v s$. mod, one-way ANOVA, and Dunnett's test, mean \pm SD, $n=3-5$. con, control; mod, model; INDO, indomethacin.

mice. Pretreatment with indomethacin or LW-AFC attenuated the activation of LPS-induced microglial cells (Figure 3(b)) and astrocytes (Figure 3(d)) in the hippocampus of mice.

3.4. Pretreatment of LW-AFC Modulated the Abnormality of Lymphocyte Subpopulations and Cytokine Secretion Caused by Intraperitoneal Injection of LPS. To figure out the immunomodulatory effects of LW-AFC on LPS-induced inflammation, we detected the contents of lymphocyte subpopulations in the spleen and peripheral blood and the concentration of cytokines in the hippocampus and plasma. The results showed that intraperitoneal injection of LPS caused an increase in the activated T-cell CD ${ }^{+} \mathrm{CD} 25^{+}$ (Figure $4(\mathrm{c}))$ in the spleen and T-cell $\mathrm{CD}^{+}$((Figure 4(a)),
T-helper cell $\mathrm{CD}^{+} \mathrm{CD}^{+}$(Figure $4(\mathrm{~b})$ ), and $\mathrm{CD}^{+} \mathrm{CD}^{+} /$ $\mathrm{CD}^{+} \mathrm{CD}^{+}$(Figure 4(d)) did not change. In blood, it reduced the expression of $\mathrm{T}$-cell $\mathrm{CD}^{+}$(Figure 4(e)), $\mathrm{CD}^{+} \mathrm{CD}^{+}$(Figure 4(f)), and $\mathrm{CD}^{+} \mathrm{CD} 25^{+}$(Figure $4(\mathrm{~g})$ ) and a little increase of the $\mathrm{CD} 3^{+} \mathrm{CD} 4^{+} / \mathrm{CD} 3^{+} \mathrm{CD} 8^{+}$ (Figure $4(\mathrm{~h})$ ). Pretreatment with LW-AFC reversed the abnormality of some lymphocyte subpopulations caused by the intraperitoneal injection of $\mathrm{LPS}$ : $\mathrm{CD} 3^{+} \mathrm{CD} 4^{+}$ (Figure 4(b)) in the spleen and $\mathrm{CD}^{+}$(Figure 4(e)), $\mathrm{CD}^{+} \mathrm{CD}^{+}$(Figure 4(f)), and $\mathrm{CD}^{+} \mathrm{CD}^{2} 5^{+}$(Figure $4(\mathrm{~g})$ ) in the blood.

The administration of an intraperitoneal injection of LPS increased the secretion of proinflammatory factor IL- 6 in the hippocampus (Figure 5(b)) and plasma (Figure 5(g)) and also induced the increase in proinflammatory factor IL-1 $\beta$ (Figure 5(a)) and MCP-1 (Figure 5(c)) in the hippocampus; 
IBA1
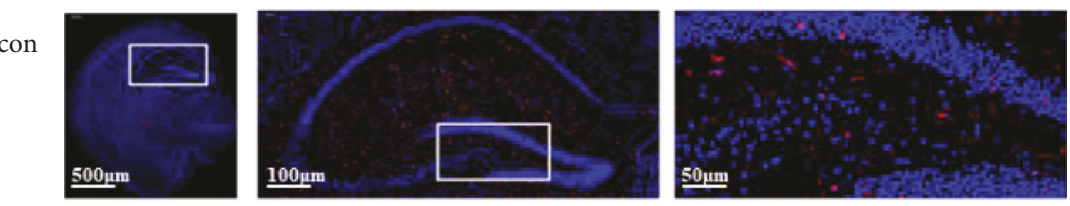

LPS
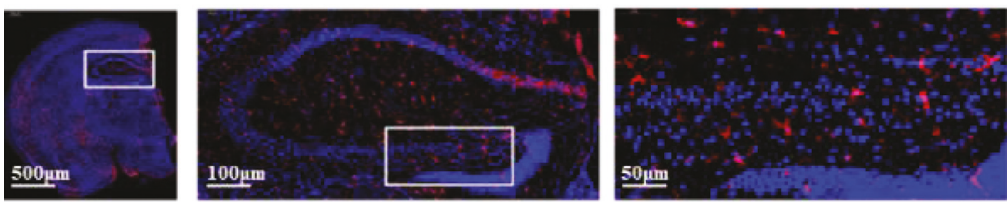

INDO
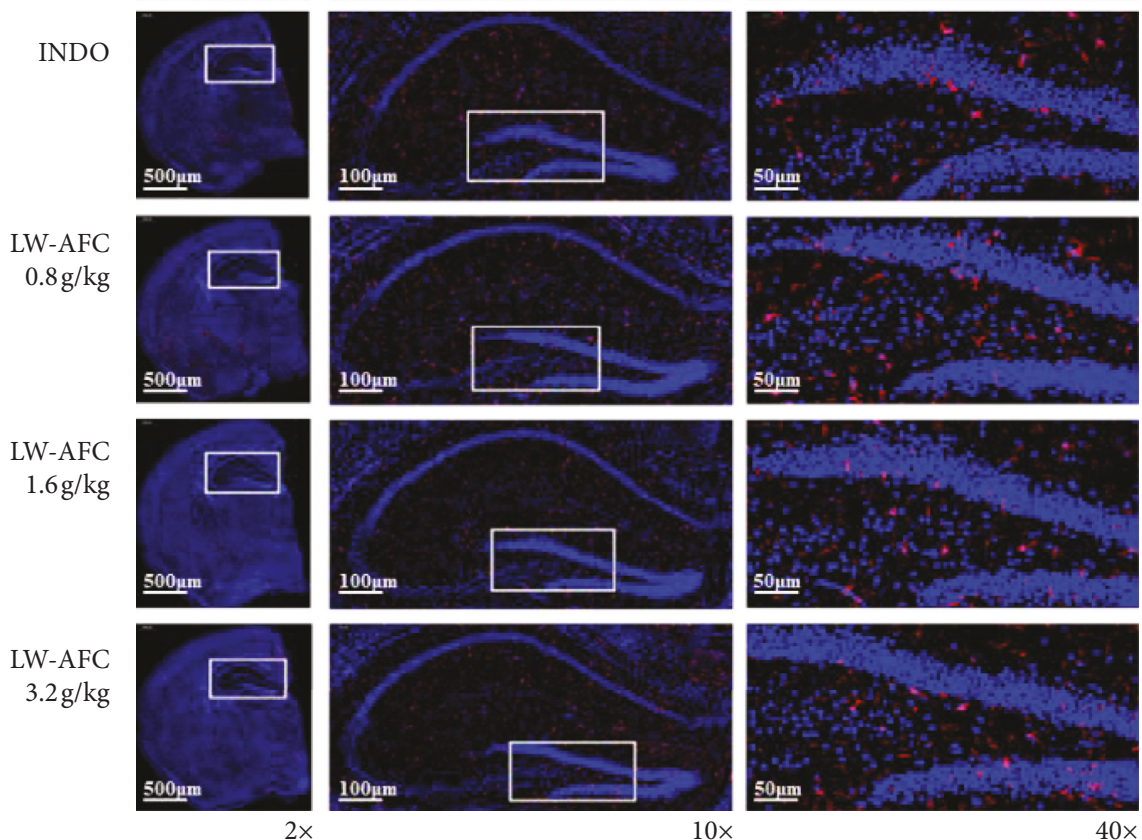

(a)
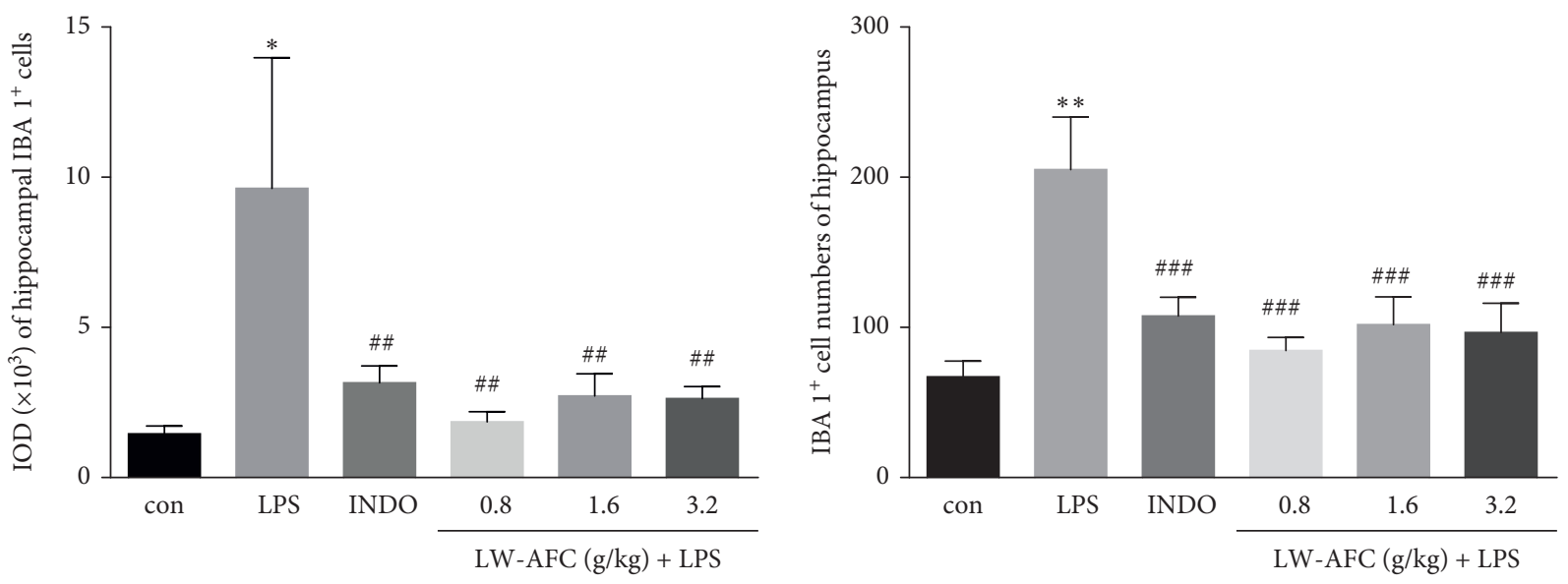

(b)

Figure 3: Continued. 

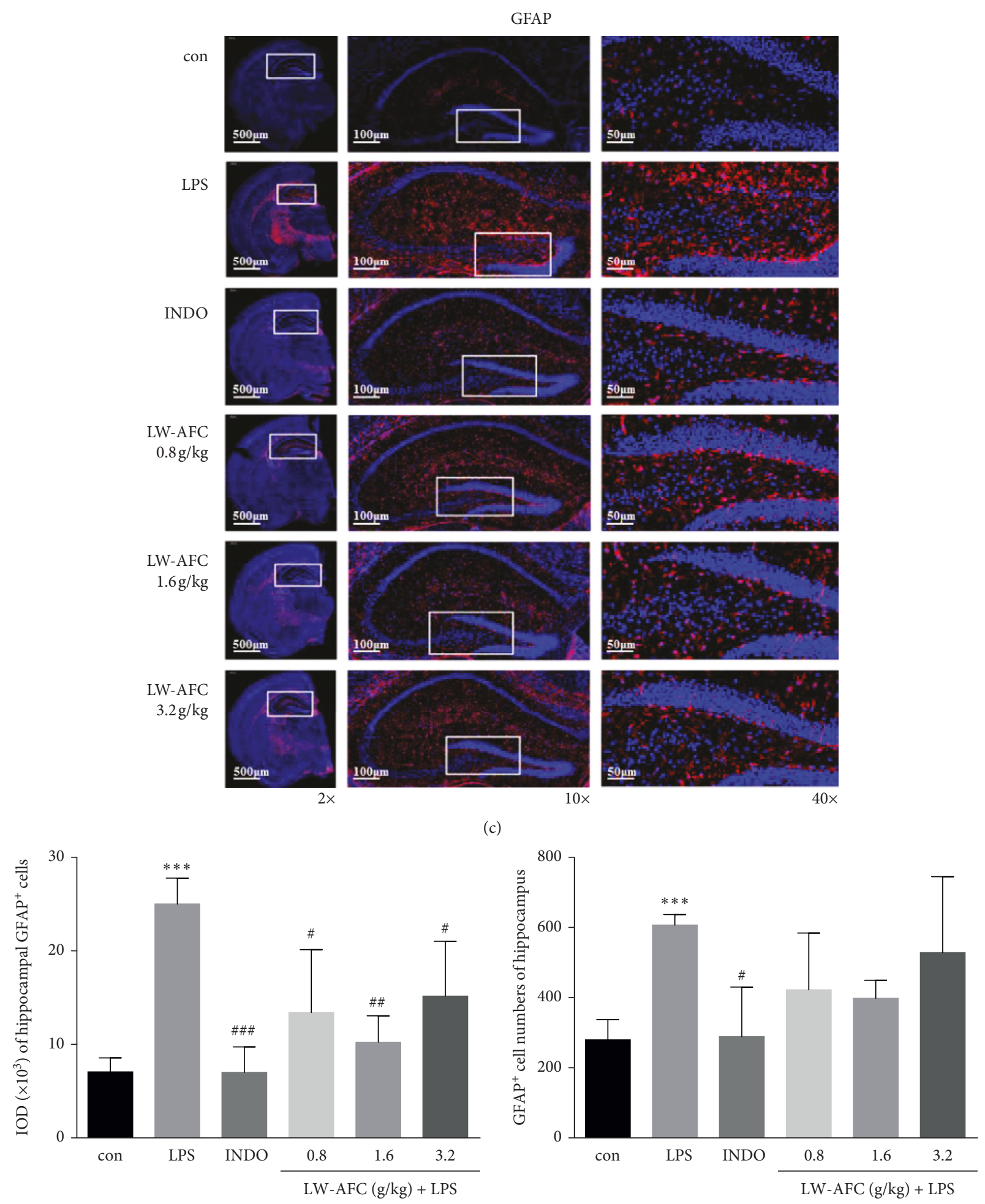

(d)

FIGURE 3: Effect of LW-AFC on microglia and astrocytes activation in the brain of LPS-induced mice. (a, c) Representative images of IBA1labeled microglia and GFAP-labeled astrocytes in the brain and hippocampus, and activated glia is shown in red. $2 \mathrm{x}, \mathrm{scale}$ bars $=500 \mu \mathrm{m}$; $10 \mathrm{x}$, scale bars $=100 \mu \mathrm{m} ; 40 \mathrm{x}$, scale bars $=50 \mu \mathrm{m}$. (b, d) Quantification of the IOD (integrated optical density) value and the IBA1+ and GFAP + cells numbers. ${ }^{* *} p<0.01$ and ${ }^{*} p<0.05 v s$. con and Student's $t$-test; ${ }^{\# \# \#} p<0.001$ and ${ }^{\# \#} p<0.01 v s$. mod, one-way ANOVA, and Dunnett's test. Mean $\pm \mathrm{SD}, n=3$. con, control; mod, model; INDO, indomethacin. 

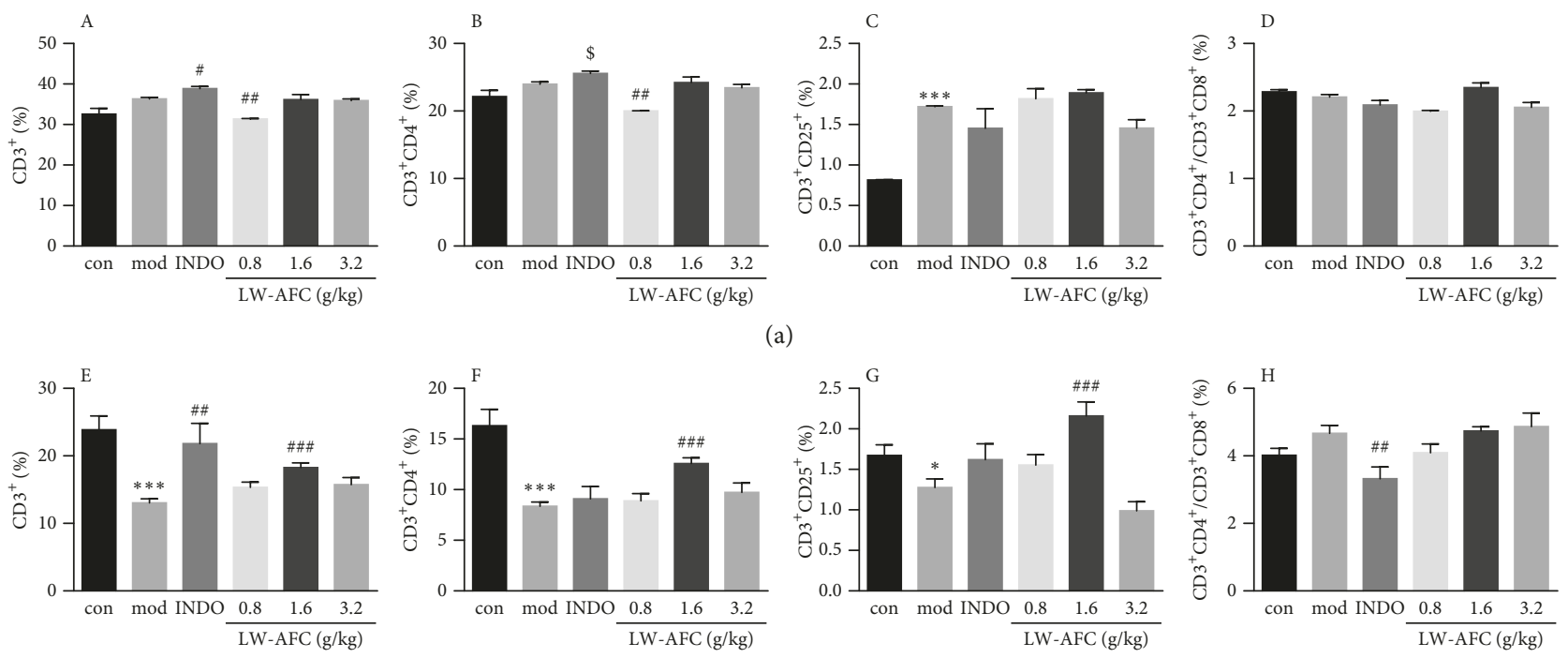

(a)
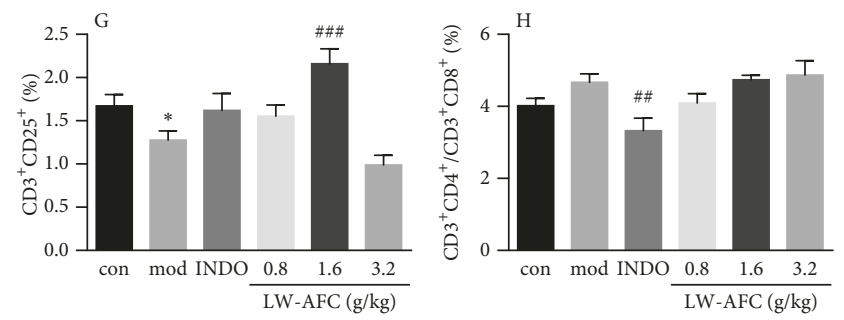

(b)

Figure 4: Effect of LW-AFC on lymphocyte subpopulations in the (a) spleen and (b) blood of LPS-treated mice. ${ }^{* * *} p<0.001,{ }^{* *} p<0.01$, and ${ }^{*} p<0.05$ vs. con and student's t-test; ${ }^{\# \# \#} p<0.001,{ }^{\# \#} p<0.01$, and ${ }^{\#} p<0.05$ vs. mod, one-way ANOVA, and Dunnett's test. (A-D) Percentage of lymphocyte subpopulations in the spleen, mean \pm SD, $n=3$. (E-H) Percentage of lymphocyte subpopulations in the blood, mean $\pm \mathrm{SD}, n=8$. con, control; mod, model; INDO, indomethacin.
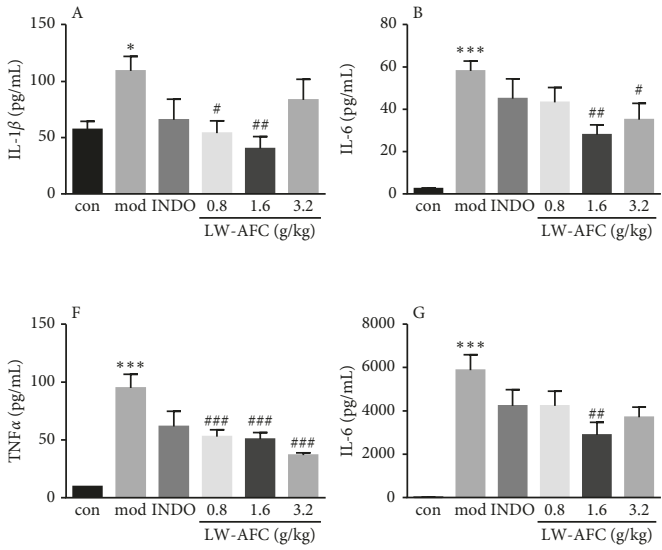

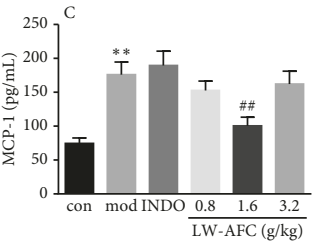

(a)

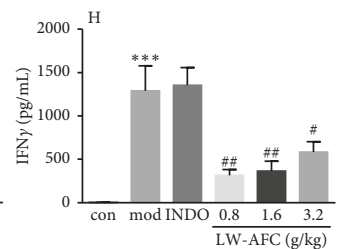

(b)
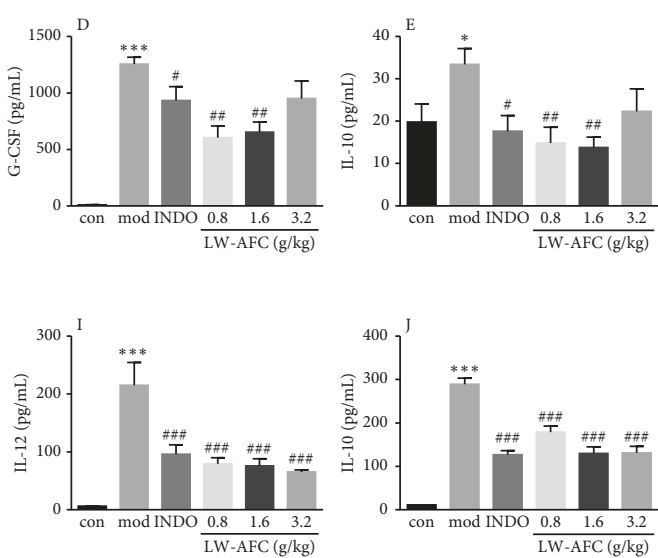

FiguRE 5: Effect of LW-AFC on cytokine secretion in the (a) hippocampus and (b) plasma of LPS-treated mice. ${ }^{* * *} p<0.001,{ }^{* *} p<0.01$, and ${ }^{*} p<0.05$ vs. con and Student's $t$-test; ${ }^{\# \# \# ~} p<0.001,{ }^{\# \#} p<0.01$, and ${ }^{\#} p<0.05 v s$. mod, one-way ANOVA, and Dunnett's test, mean \pm SD, $n=5-8$. A, IL-1 $\beta$; B, IL-6; C, MCP-1; D, G-CSF; E, IL-10; F, TNF- $\alpha$; G, IL-6; H, IFN $\gamma$; I, IL-12; J, IL-10. con, control; mod, model; INDO, indomethacin.

anti-inflammatory cytokine G-CSF (Figure 5(d)) and IL-10 (Figure 5(e)) in the hippocampus; proinflammatory factor TNF- $\alpha$ (Figure 5(f)), IFN- $\gamma$ (Figure 5(h)), and IL-12 (Figure 5(i)) in plasma; and anti-inflammatory cytokine IL-10 (Figure 5(j)) in plasma. The data indicate that pretreatment with LW-AFC reverses the aberrant secretion of cytokine including proinflammatory factor IL-1 $\beta$ (Figure 5(a)), IL-6 (Figure 5(b)), and MCP-1 (Figure 5(c)) in the hippocampus; anti-inflammatory cytokine IL-10 (Figure 5(e)) and G-CSF (Figure $5(\mathrm{~d})$ ) in the hippocampus; proinflammatory factor TNF- $\alpha$ (Figure 5(f)), IL-6 (Figure 5(g)), IFN- $\gamma$ (Figure 5(h)), and IL-12 (Figure 5(i)) in plasma; and anti-inflammatory cytokine IL-10 (Figure 5(j)) in plasma. We also detected the cytokines in the cortex; LW-AFC only decreased the level of MCP-1 in the cortex (Figure S5) and had no significant effect on other cytokines.

3.5. Effect of LW-AFC Compounds on Cell Viability and Secretion of TNF- $\alpha$ in LPS-Stimulated BV-2 Cells. Microglia are important immune cells in the CNS. TNF- $\alpha$ is the earliest and most important inflammatory mediator in the process of inflammation, not only promoting the occurrence of inflammation but also a key physiological regulator of hippocampal synaptic function [30]. Therefore, to further study the immunomodulatory effect of LW-AFC, we evaluated 


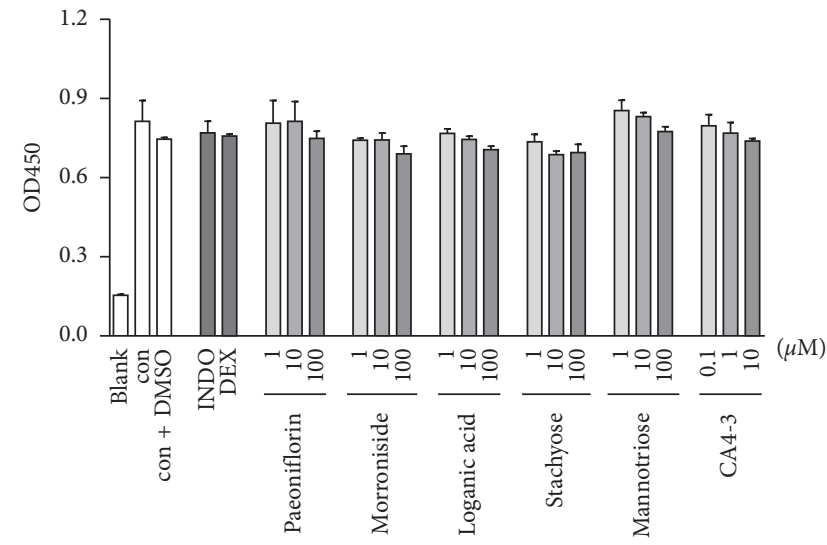

(a)

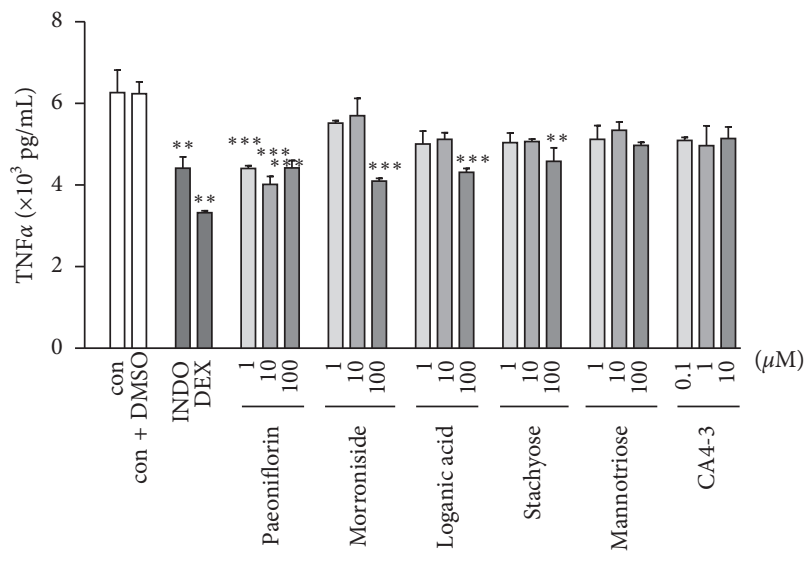

(c)

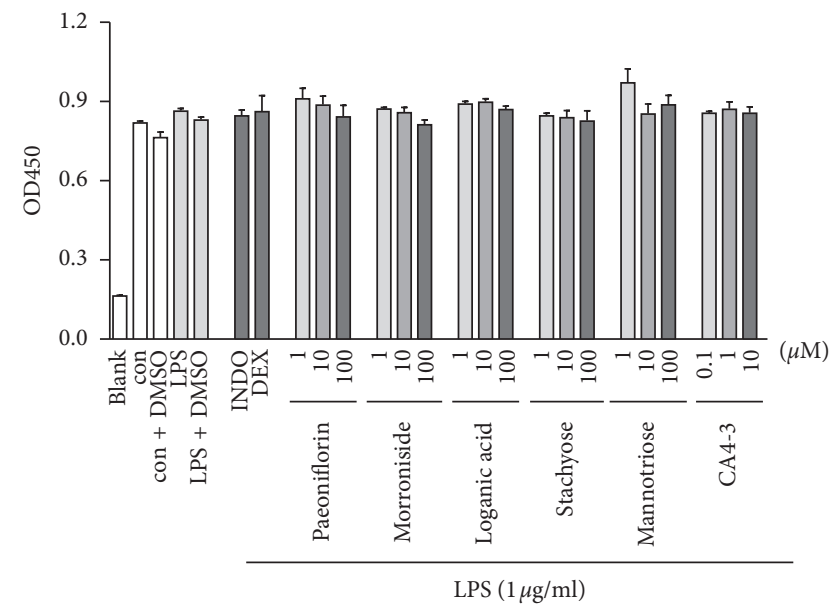

(b)

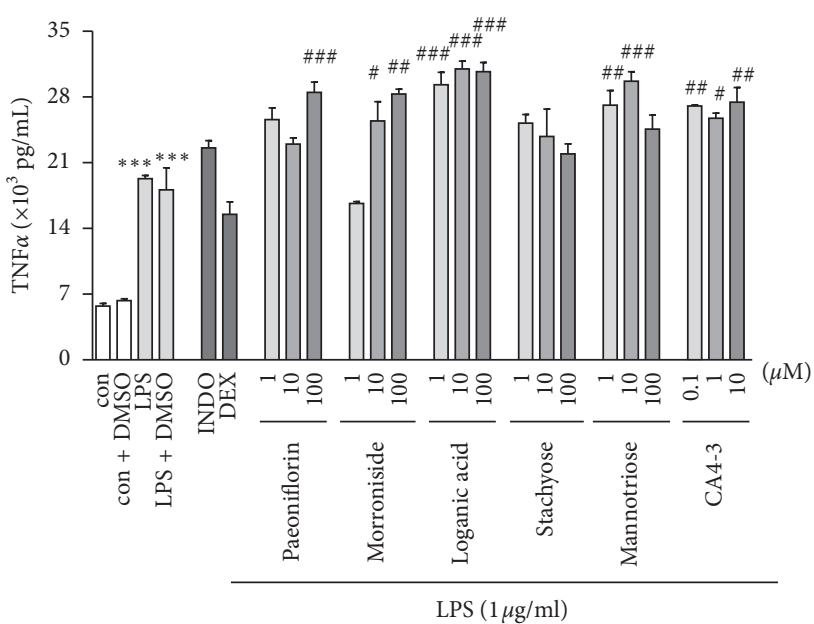

(d)

FIGURE 6: Effect of compounds from LW-AFC on cell viability and secretion of TNF- $\alpha$ in LPS-stimulated and non-LPS-stimulated BV2 cells: (a) the cell viability of non-LPS-stimulated BV-2 cells; (b) the cell viability of LPS-stimulated BV-2 cells; (c) secretion of TNF- $\alpha$ in non-LPS-stimulated BV-2 cells; (d) secretion of TNF- $\alpha$ in LPS-stimulated BV-2 cells. ${ }^{* * *} p<0.001$ and ${ }^{* *} p<0.01 v s$. con and Student's $t$-test; ${ }^{\# \# \#} p<0.001,{ }^{\# \#} p<0.01$, and ${ }^{\#} p<0.05, v s$. mod, one-way ANOVA, and Dunnett's test. Mean \pm SD $n=3$. con, control; mod, model; INDO, indomethacin; DEX, dexamethasone.

the effects of representative compounds from glycosides, oligosaccharides, and polysaccharides-the three active fractions of LW-AFC on BV-2 cells. The data show that paeoniflorin, morroniside, and loganic acid from the glycosides; stachyose and mannotriose from the oligosaccharides; and CA4-3 from the polysaccharides did not result in any cytotoxic effects on non-LPS-stimulated (Figure 6(a)) and LPS-stimulated BV2 cells (Figure 6(b)). Pretreatment with paeoniflorin at dosage of $1 \mu \mathrm{M}, 10 \mu \mathrm{M}$, and $100 \mu \mathrm{M}$, morroniside, loganic acid, and stachyose, respectively, at a dosage of $100 \mu \mathrm{M}$ significantly reduced the TNF- $\alpha$ secretion in non-LPS-stimulated BV- 2 cells (Figure 6(c)). At dosage of $0.1 \mu \mathrm{M}$, only the pretreatment with CA4-3 increased TNF- $\alpha$ secretion of BV-2 cells stimulated by LPS. At dosage of $1 \mu \mathrm{M}$, loganic acid, mannotriose, and CA4-3, respectively, increased TNF- $\alpha$ secretion. At dosage of $10 \mu \mathrm{M}$, morroniside, loganic acid, mannotriose, and CA4-3 had the effect of increasing TNF- $\alpha$ secretion. At dosage of $100 \mu \mathrm{M}$, paeoniflorin, morroniside, and loganic acid increased of TNF- $\alpha$ secretion of BV-2 cells stimulated by LPS (Figure 6(d)).

\section{Discussion}

The results suggest that LW-AFC improves the LPS-induced inhibition of LTP in the hippocampus, reduces the activation of glial cells, and regulates the abnormality of cytokines and lymphocyte subtypes, which have good anti-neuroinflammatory activation. Under normal physiological conditions, the immune response is beneficial for regulating the remodeling of neural circuits, promoting memory consolidation, hippocampal LTP, and neurogenesis, which are mediated by complex interactions among the brain cells with microglia and astrocytes, peripheral immune cells, in particular $\mathrm{T}$ cells and macrophages, and neurons [31, 32]. Proinflammatory cytokines disrupt the delicate balance needed for the neurophysiological actions of immune processes and produce direct detrimental effects on memory and synaptic plasticity [33]. LTP is one of the most widely used models for studying synaptic plasticity, and it is a key cellular process in learning and memory. Both central and 
peripheral administration of LPS can lead to cognitive impairment [34, 35] and synaptic plasticity inhibition [36-38]. In this study, the dosage of LPS was used by referencing the literature [34], and the results showed that LTP was significantly inhibited after the i.p. injection of LPS, in line with the results reported in previous studies [37, 39]. Pretreatment with LW-AFC could improve impaired LTP induced by LPS. Evidence has shown that acute neuroinflammation impairs context discrimination memory via the disruption of the pattern separation process at the neural circuit activity level in the CA3 and CA1 of LPS-treated rats, showing strong retrieval deficits of context discrimination at the behavioral level $[14,40]$. In our experiment, we performed whether the temporal order memory was impaired in LPS-injected mice. Evidence has shown that temporal order memory tested in a spatial navigation task may provide a selective behavioral marker of Alzheimer's disease [41]. Our results showed that the LW-AFC pretreatment only has tendency to improve the short-term memory impairment in our behavioral test, and this might be partially due to the duration and dosage of drug administration. However, LTP is more sensitive than the behavioral test, LW-AFC could significantly improve the LPS-induced impairment of LTP at the dosage of $1.6 \mathrm{~g} / \mathrm{kg} \mathrm{LW-AFC} \mathrm{ad-}$ ministration, and it suggests that short-term administration of LW-AFC can significantly improve the inhibition of LTP, but it may take long duration for LW-AFC to work at the behavioral level. Besides, excessive inflammatory responses in the cortex also could lead to behavioral impacts [42], and our results showed that the effect of LW-AFC on the secretion of inflammatory factors in the hippocampus was better than that in the cortex, which might be another reason why LW-AFC did not work significantly in this performance. Fever is one of the most common symptoms accompanying inflammation, so we examined changes in body temperature in mice after acute LPS injection. The results indicated that LW-AFC had a good antipyretic effect on fever caused by inflammation; however, the effect of LWAFC on fever at $0.8 \mathrm{~g} / \mathrm{kg}$ was better than 1.6 and $3.2 \mathrm{~g} / \mathrm{kg}$ and has a better effect at $1.6 \mathrm{~g} / \mathrm{kg}$ on LTP, and the reason might be LW-AFC at the different dosages has different effects. The pharmacodynamics of some traditional Chinese medicines do not follow the concentration-dependent curve, like sometimes the pharmacological effect decreases with the dose increasing to a certain extent. Fever and LTP are two different events; of course, fever can affect LTP and they are related but involve different mechanisms and different pathways. LW-AFC at different dosages may have different effects on different symptoms and also act in different ways. In our study, $1.6 \mathrm{~g} / \mathrm{kg} \mathrm{LW-AFC} \mathrm{has} \mathrm{a} \mathrm{better} \mathrm{effect} \mathrm{on} \mathrm{LTP,}$ and our previous studies showed that LW-AFC improved cognitive performance in sporadic and family AD model mice at this dose $[25,26]$ and also LW-AFC at this dosage significantly ameliorated the corticosterone-induced LTP inhibition mice model and the LTP impairment in SAMP8 mice, respectively [27], so we recommend $1.6 \mathrm{~g} / \mathrm{kg}$ as the optimal dose of LW-AFC, and this dosage is equivalent to $10 \mathrm{~g} / \mathrm{kg}$ Liuwei Dihuang decoction for humans in the clinical effective range.
Glial cells play important roles in various physiological and pathophysiological functions [43]. Microglia are the only nucleus phagocytes within the CNS that are important to the CNS immune response. The immune defense and maintenance of neuronal function are the two main functions within the CNS [44]. Microglia-derived molecules regulate synaptic connectivity including the regulation of synaptogenesis, synaptic pruning, axon outgrowth, synapse maturation, basal synaptic transmission, and functional synapse plasticity [45-47]. Microglia activation not only induces the production of cytokines but also cross talks with astrocyte activation [48]. Reactive astrocytes are abundant in various human neurodegenerative diseases and lose most normal astrocytic functions; activated microglia induce reactive astrocytes by secreting cytokines [48]. Previous studies demonstrated that systemic LPS injection can activate microglia and consequently induce proinflammatory cytokine secretion within six hours via the NFkB pathway in the mouse hippocampus [49-51]. Our results are in line with previous reports, where the inflammatory factors IL- $1 \beta$, IL6 , and MCP-1 were significantly elevated after LPS treatment, and such changes were accompanied by hippocampal LTP impairment or neuronal injury [52]. LW-AFC could minimize LPS-induced inflammatory mediators in the hippocampus that are secreted by activated glial cells, and this may be related to improving the inhibition of synaptic plasticity in LPS-treated mice.

Immune cells reach the CNS via blood and the meningeal lymphatic vessels, which was discovered [53]. Activated Th cells can simultaneously produce multiple cytokines, and some of the inflammatory cytokines are closely related to learning and memory, especially in the hippocampus $[54,55]$, where evidence has shown that cognitive functions should be impaired in the absence of T cells [56]. Many cytokines, like IL-1 and IL-6, are involved both in the genesis of pathogenic Th cells and their maintenance and act in both the peripheral immune and CNS $[33,57]$. TNF acts synergistically with IFN- $\gamma$ to promote the expression of MHC molecules on astrocytes and oligodendrocytes [58], which may increase their susceptibility to $\mathrm{CD}^{+}$T-cell-mediated cytotoxicity. Our data showed that pretreatment with $\mathrm{LW}-\mathrm{AFC}$ reverses the decrease in T-helper cell $\mathrm{CD}^{+} \mathrm{CD}^{+}$and $\mathrm{B}$-cell $\mathrm{CD} 19^{+}$in the spleen; T-cell $\mathrm{CD}^{+}{ }^{+}$, T-helper cell $\mathrm{CD} 3^{+} \mathrm{CD} 4^{+}$, and activated T-cell $\mathrm{CD}^{+} \mathrm{CD}^{2} 5^{+}$in blood caused by LPS; reduced the proinflammatory cytokine TNF- $\alpha$, IL-6, IL-12, INF- $\gamma$, and the anti-inflammatory cytokine IL-10 in plasma, suggesting that LW-AFC has a good immunoregulation effect on systemic inflammatory responses.

Cytokines can modulate synaptic transmission via glianeuron signaling [19] and are fundamental in the dynamic interaction between neurons, glia, endothelial cells, and lymphocytes. The increased level of IL- $1 \beta$ is the driving force in cognitive dysfunction pathogenesis $[59,60]$. IL- $1 \beta$ is the main final effector of the inflammation-induced deficits in both LTP and memory $[54,61]$, and LW-AFC seems to have a strong inhibitory effect on IL- $1 \beta$ in the hippocampus. IL-12 is produced by antigen-presenting cells and B cells, which are a heterodimeric form of proinflammatory cytokines. It is related 
to the amyloid load in AD pathology, and inhibition of the IL12/IL-23 pathway may attenuate pathology and improve cognitive behavior [62]. IL-10 generally acts as an anti-inflammatory factor, but IL-10 overexpression can reduce microglial phagocytosis, leading to $\mathrm{A} \beta$ aggregation and worsening cognitive behavior in APP mice. Blocking the IL-10 anti-inflammatory response is beneficial for rebalancing the innate immunity $[63,64]$. Clinical evidence suggests that significantly increased MCP-1 levels are associated with AD pathological changes and involved in memory dysfunction $[65,66]$. Pretreatment with LW-AFC reduced the aberrant secretion of proinflammatory factor MCP-1 in the cerebral cortex, IL-1 $\beta$, IL- 6 , and MCP- 1 in the hippocampus, as well as the anti-inflammatory cytokine IL-10 and G-CSF in the hippocampus.

Moreover, we found that LW-AFC has a good regulatory effect on neuroinflammation, and we hope to further explore the important material basis for LW-AFC. Therefore, we preliminarily evaluated the immune activity of some compounds of LW-AFC in vitro experiments. It is well known that the compatibility of traditional Chinese medicines can produce special effects different from a single Chinese medicine. Some traditional Chinese medicine has a bidirectional regulation effect, and the pharmacological effects are not concentration/dose-dependent. We found that the individual compounds at high dose decreased the secretion of TNF-alpha in non-LPSstimulated BV-2 cells but increased the secretion of TNFalpha in LPS-stimulated BV-2 cells; the results were caused partly by the compounds that have different effects at different concentrations when used alone, and they may have superposition or antagonistic effect when they interact with other compounds. The data showed that compounds have different effects on TNF- $\alpha$ secreted by non-LPS- and LPS-stimulated cells, which might be instructive for future research. Because the role of cytokines is extremely complex in the regulation of neuroimmune and neurodegenerative diseases, additional investigation is necessary to understand its cellular and molecular mechanisms, and understanding the dynamic interaction between LW-AFC and cytokines or glial cells and how they affect cognitive processes has many clinical implications.

\section{Conclusions}

Taken together, the results of the present study for the first time showed that pretreatment with LW-AFC improves the impaired LTP and alleviates the activation of microglia and astrocytes in the hippocampus of mice induced by LPS. The pretreatment of LW-AFC modulated the abnormality of lymphocyte subpopulations including $\mathrm{T}$ cells, T-helper cells, activated T cells, and the aberrant secretion of proinflammatory and anti-inflammatory factors caused by LPS. These findings suggest that LW-AFC improves the impaired synaptic plasticity, and activated glial cells in the hippocampus induced by LPS is possibly associated with modulating the levels of cytokines secreted in the hippocampus and blood and regulating the lymphocyte subpopulations in blood, which might be part of the mechanism of LW-AFC improves cognitive function. Therefore, LW-AFC might be a potential therapeutic agent for neuroinflammation.

\section{Data Availability}

The data used to support the findings of this study are included within the article and the supplementary information file.

\section{Conflicts of Interest}

The authors declare that there are no conflicts of interest regarding the publication of this paper.

\section{Authors' Contributions}

W. Z., Y. Z., and X. C. conceived the study, participated in its design and coordination, and helped to draft the manuscript. J. Z. performed all experiments and wrote and revised the manuscript. B. C., Y. H., C. W., and N. S. participated in the LTP experiment. X. Z. participated in the flow cytometric analysis. G. L. participated in the immunofluorescence assay. X. C. participated in the design of the study and wrote and revised the manuscript. All authors read and approved the final manuscript.

\section{Acknowledgments}

This research was funded by the National Natural Science Foundation of China (81473191) and the National Key Research and Development Program (2016YFC1306300).

\section{Supplementary Materials}

Figure S1: the effects of LW-AFC on the temporal order memory test in LPS-treated mice. Figure S2: the effects of LPS at different doses on long-term potentiation in mice. Figure S3: the schematic diagram of LW-AFC preparation. Figure S4: the HPLC fingerprint of LW-AFC. Figure S5: the effect of LW-AFC on cytokine secretion in the cerebral cortex of mice with intraperitoneal injection of LPS. (Supplementary Materials)

\section{References}

[1] M. T. Heneka, M. J. Carson, J. E. Khoury et al., "Neuroinflammation in Alzheimer's disease," The Lancet Neurology, vol. 14, no. 4, pp. 388-405, 2015.

[2] M.-V. Guillot-Sestier, K. R. Doty, and T. Town, "Innate immunity fights Alzheimer's disease," Trends in Neurosciences, vol. 38, no. 11, pp. 674-681, 2015.

[3] G. Lueg, C. C. Gross, H. Lohmann et al., "Clinical relevance of specific T-cell activation in the blood and cerebrospinal fluid of patients with mild Alzheimer's disease," Neurobiology of Aging, vol. 36, no. 1, pp. 81-89, 2015.

[4] K. J. Bryson and M. A. Lynch, "Linking T cells to Alzheimer's disease: from neurodegeneration to neurorepair," Current Opinion in Pharmacology, vol. 26, pp. 67-73, 2016. 
[5] M. Lee, E. McGeer, and P. L. McGeer, "Activated human microglia stimulate neuroblastoma cells to upregulate production of beta amyloid protein and tau: implications for Alzheimer's disease pathogenesis," Neurobiology of Aging, vol. 36, no. 1, pp. 42-52, 2015.

[6] I. Lelios and M. Greter, "Trained microglia trigger memory loss," Immunity, vol. 48, no. 5, pp. 849-851, 2018.

[7] M. Barron, J. Gartlon, L. A. Dawson, P. J. Atkinson, and M.-C. Pardon, "A state of delirium: deciphering the effect of inflammation on tau pathology in Alzheimer's disease," Experimental Gerontology, vol. 94, pp. 103-107, 2017.

[8] J. M. Parrott, L. Redus, D. Santana-Coelho, J. Morales, X. Gao, and J. C. O'Connor, "Neurotoxic kynurenine metabolism is increased in the dorsal hippocampus and drives distinct depressive behaviors during inflammation," Translational Psychiatry, vol. 6, no. 10, p. e918, 2016.

[9] V. Avdoshina, A. Bachis, and I. Mocchetti, "Synaptic dysfunction in human immunodeficiency virus type-1positive subjects: inflammation or impaired neuronal plasticity?," Journal of Internal Medicine, vol. 273, no. 5, pp. 454-465, 2013.

[10] C. Balducci, A. Frasca, M. Zotti et al., "Toll-like receptor 4dependent glial cell activation mediates the impairment in memory establishment induced by $\beta$-amyloid oligomers in an acute mouse model of Alzheimer's disease," Brain, Behavior, and Immunity, vol. 60, pp. 188-197, 2017.

[11] S. Navakkode, C. Liu, and T. W. Soong, "Altered function of neuronal L-type calcium channels in ageing and neuroinflammation: implications in age-related synaptic dysfunction and cognitive decline," Ageing Research Reviews, vol. 42, pp. 86-99, 2018.

[12] S. Tanaka, M. Ide, T. Shibutani et al., "Lipopolysaccharideinduced microglial activation induces learning and memory deficits without neuronal cell deathin rats," Journal of Neuroscience Research, vol. 83, no. 4, pp. 557-566, 2006.

[13] A. Strehl, M. Lenz, Z. Itsekson-Hayosh et al., "Systemic inflammation is associated with a reduction in Synaptopodin expression in the mouse hippocampus," Experimental Neurology, vol. 261, pp. 230-235, 2014.

[14] J. Czerniawski, T. Miyashita, G. Lewandowski, and J. F. Guzowski, "Systemic lipopolysaccharide administration impairs retrieval of context-object discrimination, but not spatial, memory: evidence for selective disruption of specific hippocampus-dependent memory functions during acute neuroinflammation," Brain, Behavior, and Immunity, vol. 44, pp. 159-166, 2015.

[15] L. Qin, X. Wu, M. L. Block et al., "Systemic LPS causes chronic neuroinflammation and progressive neurodegeneration," Glia, vol. 55, no. 5, pp. 453-462, 2007.

[16] C. Fourrier, J. Remus-Borel, A. D. Greenhalgh et al., "Docosahexaenoic acid-containing choline phospholipid modulates LPS-induced neuroinflammation in vivo and in microglia in vitro," Journal of Neuroinflammation, vol. 14, no. 1, p. 170, 2017.

[17] R. Niranjan, R. Nagarajan, K. Hanif, C. Nath, and R. Shukla, "LPS induces mediators of neuroinflammation, cell proliferation, and GFAP expression in human astrocytoma cells U373MG: the anti-inflammatory and anti-proliferative effect of guggulipid," Neurological Sciences, vol. 35, no. 3, pp. 409-414, 2014.

[18] H. F. Green and Y. M. Nolan, "Inflammation and the developing brain: consequences for hippocampal neurogenesis and behavior," Neuroscience \& Biobehavioral Reviews, vol. 40, pp. 20-34, 2014.
[19] S. Werneburg, P. A. Feinberg, K. M. Johnson, and D. P. Schafer, "A microglia-cytokine axis to modulate synaptic connectivity and function," Current Opinion in Neurobiology, vol. 47, pp. 138-145, 2017.

[20] K. R. Obermann, J. C. Morris, and C. M. Roe, "Exploration of 100 commonly used drugs and supplements on cognition in older adults," Alzheimer's \& Dementia, vol. 9, no. 6, pp. 724-732, 2013.

[21] T. Hochstrasser, L. A. Hohsfield, B. Sperner-Unterweger, and C. Humpel, " $\beta$-amyloid induced effects on cholinergic, serotonergic, and dopaminergic neurons is differentially counteracted by anti-inflammatory drugs," Journal of Neuroscience Research, vol. 91, no. 1, pp. 83-94, 2013.

[22] J. Butchart, L. Brook, V. Hopkins et al., "Etanercept in Alzheimer disease: a randomized, placebo-controlled, doubleblind, phase 2 trial," Neurology, vol. 84, no. 21, pp. 2161-2168, 2015.

[23] ADAPT-FS Research Group, "Follow-up evaluation of cognitive function in the randomized alzheimer's disease antiinflammatory prevention trial and its follow-up study," Alzheimer's \& Dementia: the Journal of the Alzheimer's Association, vol. 11, no. 2, pp. 216-225, 2015.

[24] X. Shao, X. L. Chi, W. X. Zhou et al., "Effect of LW-AFC on immune function in cyclophosphamide treated mice," Chinese Journal of Pharmacology \& Toxicology, vol. 24, no. 5, pp. 333-338, 2010.

[25] J. H. Wang, X. Lei, X. R. Cheng et al., "LW-AFC, a new formula derived from Liuwei Dihuang decoction, ameliorates behavioral and pathological deterioration via modulating the neuroendocrine-immune abnormalities in PrP-hA $\beta$ PPswe/ PS1 $1 \mathrm{E} 9$ transgenic mice," Alzheimer's Research \& Therapy, vol. 8, no. 10, p. 57, 2016.

[26] J. Wang, X. Zhang, X. Cheng et al., "LW-AFC, a herbal medicine for Alzheimer's disease, ameliorates cognitive deterioration and modulates neuroendocrine-immune system in senescence-accelerated mouse prone 8 strain," Current Alzheimer Research, vol. 14, no. 2, p. 221, 2016.

[27] W. Zhou, X. Cheng, and Y. Zhang, "Effect of Liuwei Dihuang decoction, a traditional Chinese medicinal prescription, on the neuroendocrine immunomodulation network," Pharmacology \& Therapeutics, vol. 162, no. 4, pp. 170-178, 2016.

[28] T. Lomo, "The discovery of long-term potentiation," Philosophical Transactions of the Royal Society of London Series B-Biological Sciences, vol. 358, no. 1432, pp. 617-620, 2003.

[29] T. V. P. Bliss and T. Lømo, "Long-lasting potentiation of synaptic transmission in the dentate area of the anaesthetized rabbit following stimulation of the perforant path," Journal of Physiology, vol. 232, no. 2, pp. 331-356, 1973.

[30] P. Horia and S. David, "TNF- $\alpha$ downregulates inhibitory neurotransmission through protein phosphatase 1-dependent trafficking of $\mathrm{GABA}_{\mathrm{A}}$ receptors," Journal of Neuroscience, vol. 33, no. 40, pp. 15879-15893, 2013.

[31] A. M. Minogue, "Role of infiltrating monocytes/macrophages in acute and chronic neuroinflammation: effects on cognition, learning and affective behaviour," Progress in Neuro-Psychopharmacology and Biological Psychiatry, vol. 79, pp. 15-18, 2017.

[32] R. Yirmiya and I. Goshen, "Immune modulation of learning, memory, neural plasticity and neurogenesis," Brain, Behavior, and Immunity, vol. 25, no. 2, pp. 181-213, 2011.

[33] B. B. Becher, S. Spath, and J. Goverman, "Cytokine networks in neuroinflammation," Nature Reviews Immunology, vol. 17, no. 1, 2017. 
[34] N. L. Sparkman, R. A. Kohman, A. K. Garcia, and G. W. Boehm, "Peripheral lipopolysaccharide administration impairs two-way active avoidance conditioning in C57BL/6J mice," Physiology \& Behavior, vol. 85, no. 3, pp. 278-288, 2005.

[35] N. L. Sparkman, R. A. Kohman, V. J. Scott, and G. W. Boehm, "Bacterial endotoxin-induced behavioral alterations in two variations of the Morris water maze," Physiology \& Behavior, vol. 86, no. 1-2, pp. 244-251, 2005.

[36] A. Hennigan, C. Trotter, and Á. M. Kelly, "Lipopolysaccharide impairs long-term potentiation and recognition memory and increases p75NTR expression in the rat dentate gyrus," Brain Research, vol. 1130, no. 1, pp. 158-166, 2007.

[37] Á. Kelly, E. Vereker, Y. Nolan et al., “Activation of p38 plays a pivotal role in the inhibitory effect of lipopolysaccharide and interleukin- $1 \beta$ on long term potentiation in rat dentate gyrus," Journal of Biological Chemistry, vol. 278, no. 21, pp. 19453-19462, 2003.

[38] Y. Huang, Z. Hu, G. Liu, W. Zhou, and Y. Zhang, "Сytokines induced by long-term potentiation (LTP) recording: a potential explanation for the lack of correspondence between learning/memory performance and LTP," Neuroscience, vol. 231, pp. 432-443, 2013.

[39] K. C. Yu, L. Baum, S. K. K. Cheung, and A. Ho, "Resveratrol strongly decreases neurofibrillary tangles in a transgenic mouse model of tauopathy," Alzheimer's \& Dementia: the Journal of the Alzheimer's Association, vol. 10, no. 4, pp. P463-P464, 2014.

[40] J. Czerniawski and J. F. Guzowski, "Acute neuroinflammation impairs context discrimination memory and disrupts pattern separation processes in Hippocampus," Journal of Neuroscience, vol. 34, no. 37, pp. 12470-12480, 2014.

[41] V. Bellassen, K. Iglói, L. C. de Souza et al., "Temporal order memory assessed during spatiotemporal navigation as a behavioral cognitive marker for differential Alzheimer's disease diagnosis," Journal of Neuroscience, vol. 32, no. 6, p. 1942, 2012.

[42] G. R. I. Barker, F. Bird, V. Alexander, and E. C. Warburton, "Recognition memory for objects, place, and temporal order: a disconnection analysis of the role of the medial prefrontal cortex and perirhinal cortex," Journal of Neuroscience, vol. 27, no. 11, pp. 2948-2957, 2007.

[43] T. Schlegelmilch, K. Henke, and F. Peri, "Microglia in the developing brain: from immunity to behaviour," Current Opinion in Neurobiology, vol. 21, no. 1, pp. 5-10, 2011.

[44] M.-E. Tremblay, B. Stevens, A. Sierra, H. Wake, A. Bessis, and A. Nimmerjahn, "The role of microglia in the healthy brain," Journal of Neuroscience, vol. 31, no. 45, pp. 16064-16069, 2011.

[45] Y. Liu, Y. Zhang, X. Zheng et al., "Galantamine improves cognition, hippocampal inflammation, and synaptic plasticity impairments induced by lipopolysaccharide in mice," Journal of Neuroinflammation, vol. 15, no. 1, p. 112, 2018.

[46] Y. Liu, L.-J. Zhou, J. Wang et al., "TNF- $\alpha$ differentially regulates synaptic plasticity in the Hippocampus and spinal cord by microglia-dependent mechanisms after peripheral nerve injury," Journal of Neuroscience, vol. 37, no. 4, pp. 871-881, 2017.

[47] H. Lian, A. Litvinchuk, A. C. A. Chiang, N. Aithmitti, J. L. Jankowsky, and H. Zheng, “Astrocyte-microglia cross talk through complement activation modulates amyloid pathology in mouse models of Alzheimer's disease," Journal of Neuroscience, vol. 36, no. 2, pp. 577-589, 2016.

[48] S. A. Liddelow, K. A. Guttenplan, L. E. Clarke et al., "Neurotoxic reactive astrocytes are induced by activated microglia," Nature, vol. 541, no. 7638, pp. 481-487, 2017.

[49] V. Sorrenti, G. Contarini, S. Sut et al., "Curcumin prevents acute neuroinflammation and long-term memory impairment induced by systemic lipopolysaccharide in mice," Frontiers in Pharmacology, vol. 9, p. 183, 2018.

[50] E. O'Loughlin, J. M. P. Pakan, D. Yilmazer-Hanke, and K. W. Mcdermott, "Acute in utero exposure to lipopolysaccharide induces inflammation in the pre- and postnatal brain and alters the glial cytoarchitecture in the developing amygdala," Journal of Neuroinflammation, vol. 14, no. 1, p. 212, 2017.

[51] A. A. Tyrtyshnaia, L. V. Lysenko, F. Madamba et al., "Acute neuroinflammation provokes intracellular acidification in mouse hippocampus," Journal of Neuroinflammation, vol. 13, no. 1, p. 283, 2016.

[52] L. Tong, G. A. Prieto, and C. W. Cotman, "IL- $1 \beta$ suppresses cLTP-induced surface expression of GluA1 and actin polymerization via ceramide-mediated Src activation," Journal of Neuroinflammation, vol. 15, no. 1, p. 127, 2018.

[53] A. Louveau, S. Da Mesquita, and J. Kipnis, "Lymphatics in neurological disorders: a neuro-lympho-vascular component of multiple sclerosis and Alzheimer's disease?," Neuron, vol. 91, no. 5, pp. 957-973, 2016.

[54] A. H. Moore, M. Wu, S. S. Shaftel, K. A. Graham, and M. K. O'Banion, "Sustained expression of interleukin- $1 \beta$ in mouse hippocampus impairs spatial memory," Neuroscience, vol. 164, no. 4, pp. 1484-1495, 2009.

[55] E. Marciniak, E. Faivre, P. Dutar et al., "The Chemokine MIP-1 $\alpha /$ CCL3 impairs mouse hippocampal synaptic transmission," Scientific Reports, vol. 5, no. 1, 2015.

[56] J. Kipnis, H. Cohen, M. Cardon, Y. Ziv, and M. Schwartz, "T cell deficiency leads to cognitive dysfunction: implications for therapeutic vaccination for schizophrenia and other psychiatric conditions," Proceedings of the National Academy of Sciences of the United States of America, vol. 101, no. 21, pp. 8180-8185, 2004.

[57] E. Dursun, D. Gezen-Ak, H. Hanağası et al., "The interleukin 1 alpha, interleukin 1 beta, interleukin 6 and alpha-2-macroglobulin serum levels in patients with early or late onset Alzheimer's disease, mild cognitive impairment or Parkinson's disease," Journal of Neuroimmunology, vol. 283, pp. 50-57, 2015.

[58] C. Agresti, A. Bernardo, N. Del Russo et al., "Synergistic stimulation of MHC class I and IRF-1 gene expression by IFN-gamma and TNF-alpha in oligodendrocytes," European Journal of Neuroscience, vol. 10, no. 9, pp. 2975-2983, 1998.

[59] M. Cibelli, A. R. Fidalgo, N. Terrando et al., "Role of interleukin- $1 \beta$ in postoperative cognitive dysfunction," Annals of Neurology, vol. 68, no. 3, pp. 360-368, 2010.

[60] C. Garber, M. J. Vasek, L. L. Vollmer, T. Sun, X. Jiang, and R. S. Klein, "Astrocytes decrease adult neurogenesis during virus-induced memory dysfunction via IL-1," Nature Immunology, vol. 19, no. 2, pp. 151-161, 2018.

[61] R. M. Barrientos, E. A. Higgins, D. B. Sprunger et al., "Memory for context is impaired by a post context exposure injection of interleukin-1 beta into dorsal hippocampus," Behavioural Brain Research, vol. 134, no. 1-2, pp. 291-298, 2002.

[62] J. V. Berg, S. Prokop, K. R. Miller et al., "Inhibition of IL-12/ IL-23 signaling reduces Alzheimer's disease-like pathology and cognitive decline," Nature Medicine, vol. 18, no. 12, p. 1812, 2012.

[63] P. Chakrabarty, A. Li, C. Ceballos-Diaz et al., "IL-10 alters immunoproteostasis in APP mice, increasing plaque burden and worsening cognitive behavior," Neuron, vol. 85, no. 3, pp. 519-533, 2015. 
[64] M.-V. Guillot-Sestier, K. R. Doty, D. Gate et al., "Il10 deficiency rebalances innate immunity to mitigate Alzheimerlike pathology," Neuron, vol. 85, no. 3, pp. 534-548, 2015.

[65] B. M. Bettcher, R. Fitch, M. J. Wynn et al., "MCP-1 and eotaxin-1 selectively and negatively associate with memory in MCI and Alzheimer's disease dementia phenotypes," Alzheimer's \& Dementia: Diagnosis, Assessment \& Disease Monitoring, vol. 3, pp. 91-97, 2016.

[66] D. Galimberti, C. Fenoglio, C. Lovati et al., "Serum MCP-1 levels are increased in mild cognitive impairment and mild Alzheimer's disease," Neurobiology of Aging, vol. 27, no. 12, pp. 1763-1768, 2006. 


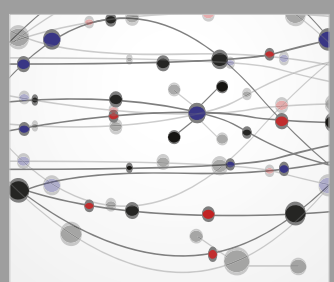

The Scientific World Journal
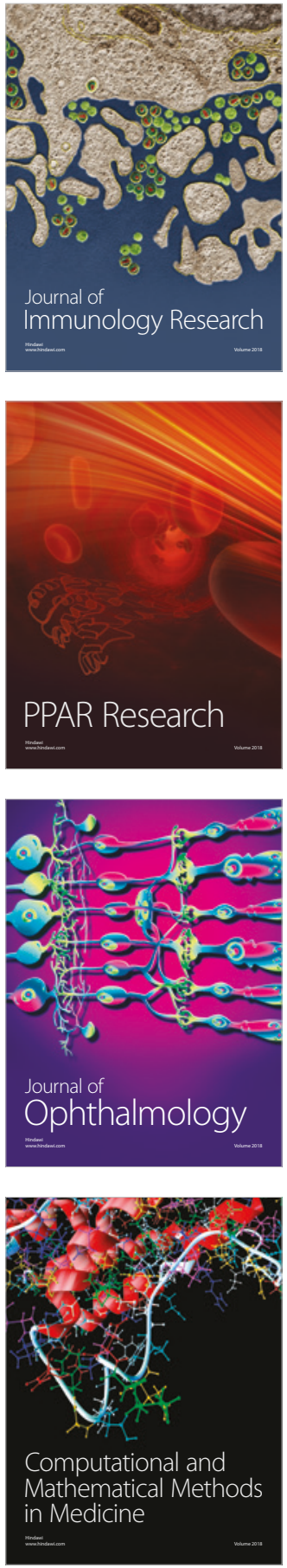

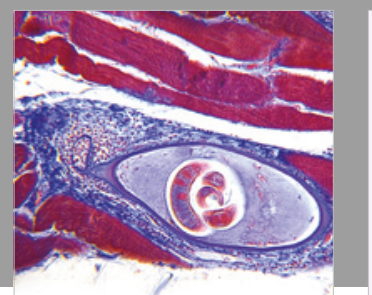

Gastroenterology Research and Practice

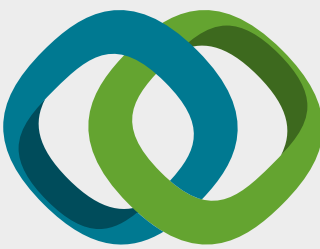

\section{Hindawi}

Submit your manuscripts at

www.hindawi.com
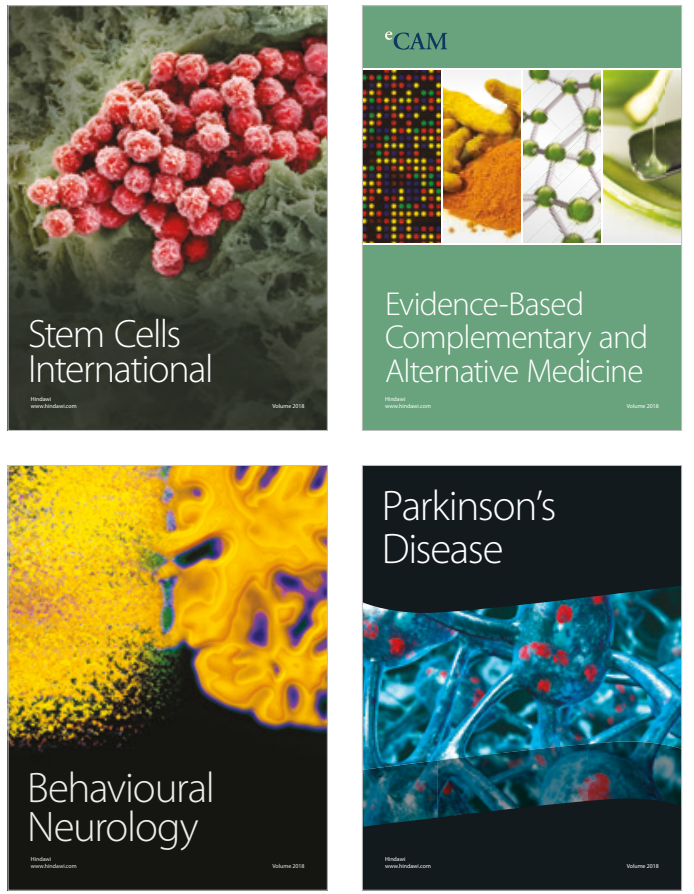

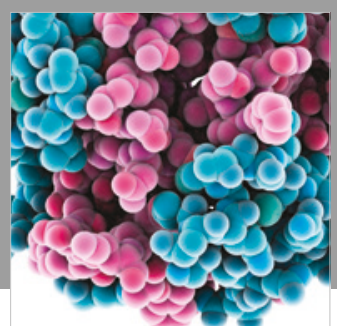

ournal of

Diabetes Research

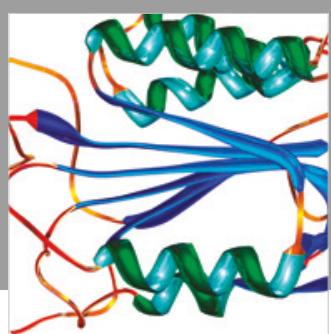

Disease Markers
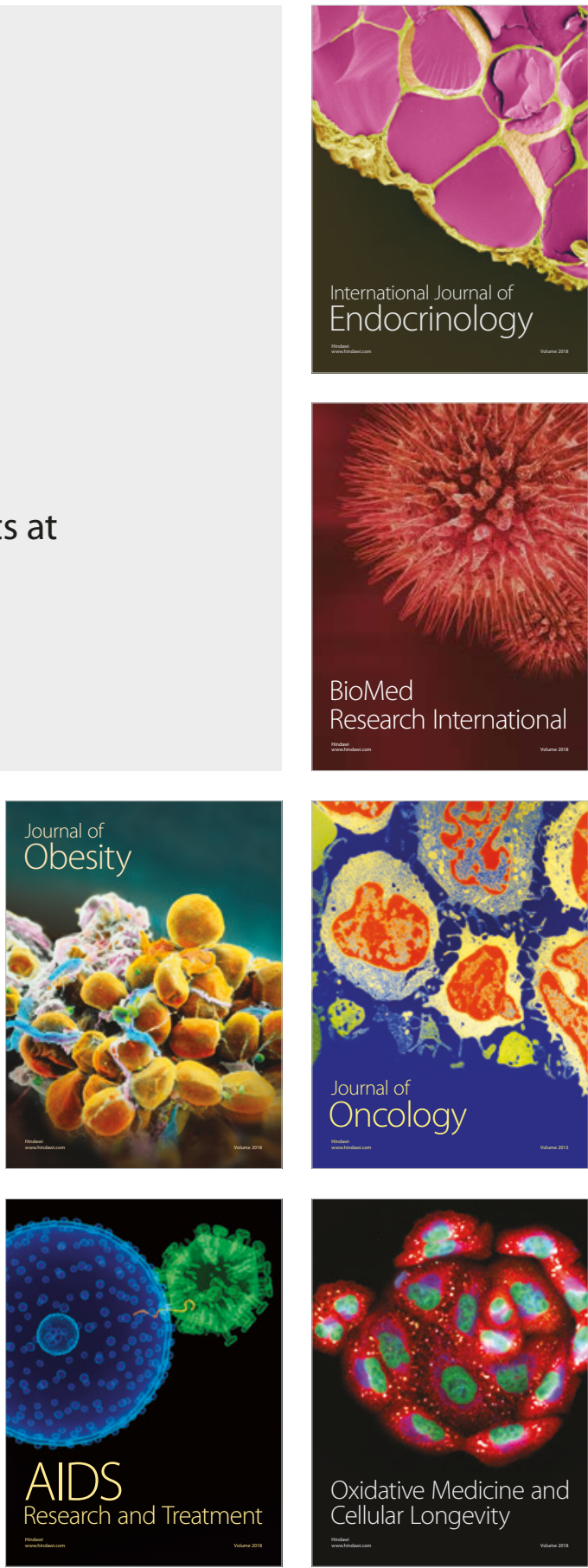